ARTICLE

https://doi.org/10.1038/s41467-019-11992-2

\title{
Highly selective oxygen reduction to hydrogen peroxide on transition metal single atom coordination
}

 \\ Eli Stavitski ${ }^{6}$, Jens K. Nørskov ${ }^{2,7}$, Samira Siahrostami (D) ${ }^{2,8}$ \& Haotian Wang (1) 1,9
}

Shifting electrochemical oxygen reduction towards $2 \mathrm{e}^{-}$pathway to hydrogen peroxide $\left(\mathrm{H}_{2} \mathrm{O}_{2}\right)$, instead of the traditional $4 \mathrm{e}^{-}$to water, becomes increasingly important as a green method for $\mathrm{H}_{2} \mathrm{O}_{2}$ generation. Here, through a flexible control of oxygen reduction pathways on different transition metal single atom coordination in carbon nanotube, we discovered FeC-O as an efficient $\mathrm{H}_{2} \mathrm{O}_{2}$ catalyst, with an unprecedented onset of $0.822 \mathrm{~V}$ versus reversible hydrogen electrode in $0.1 \mathrm{M} \mathrm{KOH}$ to deliver $0.1 \mathrm{~mA} \mathrm{~cm}^{-2} \mathrm{H}_{2} \mathrm{O}_{2}$ current, and a high $\mathrm{H}_{2} \mathrm{O}_{2}$ selectivity of above $95 \%$ in both alkaline and neutral $\mathrm{pH}$. A wide range tuning of $2 \mathrm{e}^{-} / 4 \mathrm{e}^{-} \mathrm{ORR}$ pathways was achieved via different metal centers or neighboring metalloid coordination. Density functional theory calculations indicate that the Fe-C-O motifs, in a sharp contrast to the well-known Fe-C-N for $4 \mathrm{e}^{-}$, are responsible for the $\mathrm{H}_{2} \mathrm{O}_{2}$ pathway. This iron single atom catalyst demonstrated an effective water disinfection as a representative application.

\footnotetext{
${ }^{1}$ Rowland Institute, Harvard University, Cambridge, MA 02142, USA. ${ }^{2}$ SUNCAT Center for Interface Science and Catalysis, Department of Chemical Engineering, Stanford University, Stanford, CA 94305, USA. ${ }^{3}$ Center for Nanoscale Systems, Harvard University, Cambridge, MA, USA. ${ }^{4}$ Canadian Light Source Inc., University of Saskatchewan, Saskatoon, SK S7N 2V3, Canada. ${ }^{5}$ Kostas Research Institute, Northeastern University, Burlington, MA 01803, USA. ${ }^{6}$ National Synchrotron Light Source II, Brookhaven National Laboratory, Upton, NY 11973, USA. ${ }^{7}$ SUNCAT Center for Interface Science and Catalysis, SLAC National Accelerator Laboratory, 2575 Sand Hill Road, Menlo Park, CA 94025, USA. ${ }^{8}$ Department of Chemistry, University of Calgary, 2500 University Drive NW, Calgary, Alberta T2N 1N4, Canada. ${ }^{9}$ Department of Chemical and Biomolecular Engineering, Rice University, Houston, TX 77005, USA. ${ }^{10}$ These authors contributed equally: Kun Jiang, Seoin Back Correspondence and requests for materials should be addressed to S.S. (email: samira.siahrostami@ucalgary.ca) or to H.W. (email: htwang@rice.edu)
} 
M olecular oxygen $\left(\mathrm{O}_{2}\right)$ can be electrochemically reduced to water $\left(\mathrm{H}_{2} \mathrm{O}\right)$ via a $4 \mathrm{e}^{-}$pathway, or hydrogen peroxide $\left(\mathrm{H}_{2} \mathrm{O}_{2}\right)$ with $2 \mathrm{e}^{-}$transferred in aqueous solutions. The former pathway is preferred in fuel cell applications to maximize the energy conversion efficiencies ${ }^{1-3}$, and the latter one represents a green synthetic method for $\mathrm{H}_{2} \mathrm{O}_{2}{ }^{4-7}$. Compared to the traditional energy, capital, and waste intensive anthraquinone process ${ }^{6,8,9}$, electrochemical synthesis of $\mathrm{H}_{2} \mathrm{O}_{2}$ becomes a promising alternate with significant advantages including: (1) mild reaction conditions under room temperature and ambient pressure; (2) renewable electricity as the energy source without fossil fuel consumptions; and (3) green precursors starting with water and air. Although a variety of highly active catalysts driving the $4 \mathrm{e}^{-}$oxygen reduction reaction (ORR) have been developed to improve the performance of fuel cells ${ }^{10-14}$, there are less known catalysts that can selectively reduce $\mathrm{O}_{2}$ to $\mathrm{H}_{2} \mathrm{O}_{2}$ including noble metals $s^{5,15-19}$ and carbon materials ${ }^{20-29}$. A molecular level understanding of the elementary reaction steps could provide important guidance to the design of ORR catalysts for different pathways. The critical knob for searching efficient ORR catalysts relies on the proper binding strength between the reaction site and $\mathrm{O}$ species ${ }^{27-29}$. Taking the selective $\mathrm{ORR}$ to $\mathrm{H}_{2} \mathrm{O}_{2}$, where the $\mathrm{O}-\mathrm{O}$ bond in $\mathrm{O}_{2}$ needs to be preserved, as an example here, a toostrong interaction between the reaction site and $\mathrm{O}$ species could easily dissociate the $\mathrm{O}_{2}$ molecule and direct the selectivity towards $\mathrm{H}_{2} \mathrm{O}$, while a too-weak one may create a high reaction barrier to overcome ${ }^{4,27}$. Therefore, a materials platform with flexible tunability in electronic structures is highly desired for systematic control of ORR pathways as well as improvements in catalytic activities.

Transition-metal (TM) single atom motifs coordinated in welldefined carbon matrix, with a variety of tuning knobs such as the different metal atom centers and the varied adjacent coordinative dopants, have been attracting considerable interests in heterogeneous catalysis field ${ }^{30-33}$. This is mainly due to their unique electronic properties compared to their bulk metal counterparts for extraordinary activities, as well as their capability in tuning the binding strength with reaction intermediates for boosting desired catalytic pathways ${ }^{34-36}$. One representative example is the $\mathrm{Ni}$ single atom catalyst in our previous $\mathrm{CO}_{2}$ reduction studies where the binding with $\mathrm{CO}$ was significantly weakened on isolated $\mathrm{Ni}$ atomic sites compared to that of bulk $\mathrm{Ni}$ surface to facilitate $\mathrm{CO}$ evolution ${ }^{37-39}$. With potentially a wide range of tunability in binding with $\mathrm{O}$ species via different TM single atom coordination, this class of materials as a powerful platform thus provides us with great opportunities in exploring highly selective and active catalysts for $\mathrm{H}_{2} \mathrm{O}_{2}$ generation, as well as a flexible control of ORR pathways.

Here we report the TM single atom coordination motifs for a full range control of ORR pathways from the $2 \mathrm{e}^{-}$reduction selectively to $\mathrm{H}_{2} \mathrm{O}_{2}$ towards the $4 \mathrm{e}^{-}$to $\mathrm{H}_{2} \mathrm{O}$. A series of TM single atoms including $\mathrm{Fe}, \mathrm{Pd}, \mathrm{Co}$, and $\mathrm{Mn}$ are anchored into carbon nanotube (TM-CNT) vacancies (Fe-CNT, Pd-CNT, Co-CNT, and $\mathrm{Mn}-\mathrm{CNT}$, respectively) with neighboring $\mathrm{C}, \mathrm{O}$, or $\mathrm{N}$ coordination for pathway tuning. Among the different TMs, Fe-CNT presents the state-of-the-art performance towards $\mathrm{H}_{2} \mathrm{O}_{2}$ generation in terms of activity and selectivity. An unprecedented onset potential to reach $0.1 \mathrm{~mA} \mathrm{~cm}^{-2} \mathrm{H}_{2} \mathrm{O}_{2}$ generation current is achieved at only $0.822 \mathrm{~V}$ versus reversible hydrogen electrode (vs. RHE) in $0.1 \mathrm{M} \mathrm{KOH}$ on rotating ring-disc electrode (RRDE), while a maximum $\mathrm{H}_{2} \mathrm{O}_{2}$ selectivity of more than $95 \%$ is delivered in both alkaline and neutral $\mathrm{pH}$. With the $\mathrm{O}_{2}$ mass transport facilitated by a gas diffusion layer (GDL) electrode, the $\mathrm{H}_{2} \mathrm{O}_{2}$ generation rate by $\mathrm{Fe}-\mathrm{CNT}$ can reach to $43 \mathrm{~mA} \mathrm{~cm}^{-2}$ with a $95.4 \%$ selectivity under only $0.76 \mathrm{~V}$. By switching the neighboring $\mathrm{O}$ with $\mathrm{N}$ coordination, the $2 \mathrm{e}^{-}$ORR pathway is successfully shifted towards $4 \mathrm{e}^{-}$of $\mathrm{H}_{2} \mathrm{O}$, demonstrating a wide range of reaction tunability in this materials platform. Density functional theory (DFT) calculations suggest that the catalytically active C and $\mathrm{Fe}$ sites in $\mathrm{Fe}-\mathrm{C}-\mathrm{O}$ and $\mathrm{Fe}-\mathrm{C}-\mathrm{N}$ motifs are responsible for the $\mathrm{H}_{2} \mathrm{O}_{2}$ and $\mathrm{H}_{2} \mathrm{O}$ pathways, respectively. In a variety of $\mathrm{Fe}-\mathrm{C}-\mathrm{O}$ motifs calculated, the incorporation of $\mathrm{Fe}$ atoms significantly improves their catalytic activities for $\mathrm{H}_{2} \mathrm{O}_{2}$ generation compared to those with only $\mathrm{O}$ dopants. As a prototype demonstration of potential applications, this high-performance $\mathrm{H}_{2} \mathrm{O}_{2}$ generation catalyst enables an effective water disinfection of $>99.9999 \%$ bacteria removal at a treating rate of $125 \mathrm{~L} \mathrm{~h}^{-1} \mathrm{~m}^{-2}$ electrode.

\section{Results}

Synthesis and characterizations of single atom catalysts. A small quantity of TM cations ( $\sim .1$ at\%) were first dispersed onto commercial surface-functionalized CNTs as the carbon matrix suspended in water (Supplementary Fig. 1), followed by freezedry and thermo annealing under Ar flow at $600{ }^{\circ} \mathrm{C}$ (Methods, Supplementary Note 1 and Supplementary Figs. 2-3 ${ }^{38}$. All four types of TM-CNT samples, including Fe, Pd, Co, and Mn, have shown similar structures in Fig. 1 by transmission electron microscopy (TEM) and aberration-corrected high-angle annular dark-field scanning TEM (HAADF-STEM). No nanoparticles or clusters were observed in the bright field TEM images by different scales (Fig. 1a-d; Supplementary Figs. 4-7), suggesting a well dispersion of TM atoms. Isolated TM atoms can be resolved by HAADF-STEM due to their high Z-contrast compared to those neighboring light elements such as $\mathrm{C}$ or $\mathrm{O}^{32}$. While all four isolated metal atoms were observed as the white dots in Fig. 1e-h, Pd-CNT presents the most distinguishable single atoms due to its heaviest atomic mass compared to the other three metal elements.

Although no obvious TM signals were detected by X-ray photoelectron spectroscopy (XPS, Supplementary Fig. 8) due to the low mass loading, synchrotron-based X-ray absorption spectroscopy (XAS) on the K-edge of $\mathrm{Fe}^{40}, \mathrm{Pd}^{41}, \mathrm{Co}^{42}$, and $\mathrm{Mn}^{43} \mathrm{can}$ instead provide direct evidence of the valence states and coordination environments ${ }^{38}$. The X-ray absorption near-edge structure (XANES) spectra in Supplementary Fig. 9 indicate the partial-oxidation states of these metal dopants where the pre-edge peaks are located between the corresponding metal foils and metal oxides. This is mainly due to the strong $\mathrm{M}-\mathrm{C}$ and $\mathrm{M}-\mathrm{O}$ bonds via which the electrons from the metal atomic centers are partially depleted to the neighboring $\mathrm{C}$ and $\mathrm{O}$ sites, in a good agreement with the simulated charge density distributions and Balder charge analysis (Supplementary Table 1$)^{44}$. In addition, the oxidation state of coordinated $\mathrm{Fe}$ is lower than simply adsorbed Fe on CNT, suggesting the different chemical environment between the adsorption case and coordination case (Supplementary Note 2, Supplementary Fig. 10). The corresponding Fourier transforms of extended X-ray absorption fine structure (EXAFS) for each metal are plotted in Fig. 1i-l. It is noted that the signals from bulk metal foils are dominated by M$\mathrm{M}$ bonds, i.e., $2.17 \AA$ for $\mathrm{Fe}-\mathrm{Fe}, 2.55 \AA$ for $\mathrm{Pd}-\mathrm{Pd}, 2.18 \AA$ for $\mathrm{Co}-\mathrm{Co}$ and $2.31 \AA$ for $\mathrm{Mn}-\mathrm{Mn}$, respectively ${ }^{40-43}$. In contrast, $\mathrm{M}-\mathrm{C}$ or $\mathrm{M}-\mathrm{O}$ bonds at $\sim 1.4-2.0 \AA$ are the major features in $\mathrm{M}$ CNTs, reinforcing the isolated distribution of these TM single atoms in the carbon matrix. A shoulder peak at $2.05 \AA$ is observed for $\mathrm{Mn}-\mathrm{CNT}$, which is corresponding to the $\mathrm{Mn}-\mathrm{O}$ coordination ${ }^{43}$.

Due to the capabilities in both three dimensional (3D) imaging and chemical composition measurements at the atomic scale, atom probe tomography (APT) becomes a complementary characterization to STEM and XAS to reveal additional information about the atomic structure in catalyst ${ }^{37,45-48}$. Fe-CNT was analyzed as a representative of other M-CNTs. We used a 
a

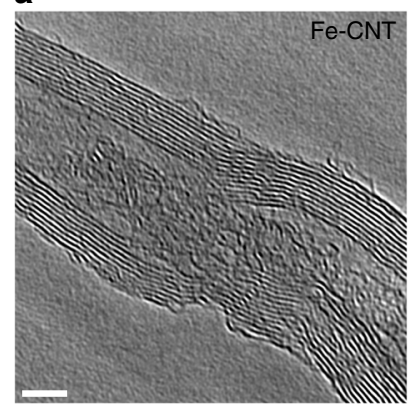

e
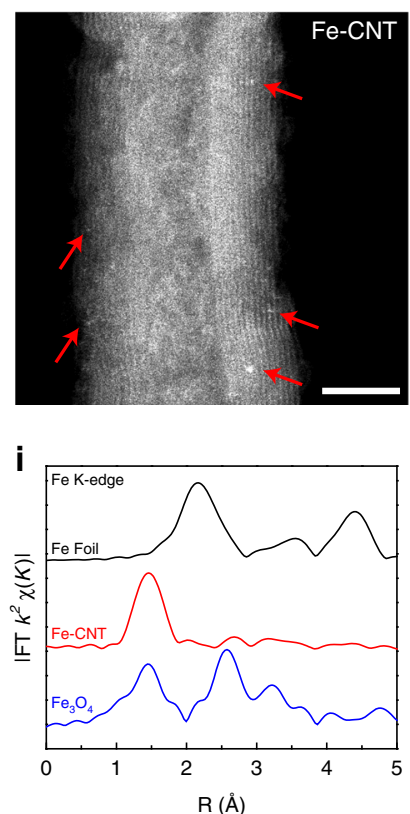

b

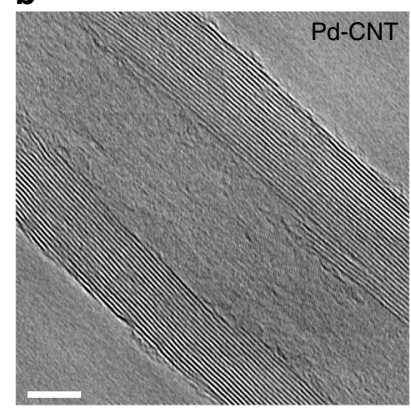

f

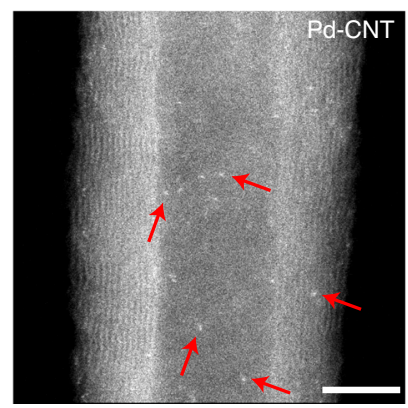

j

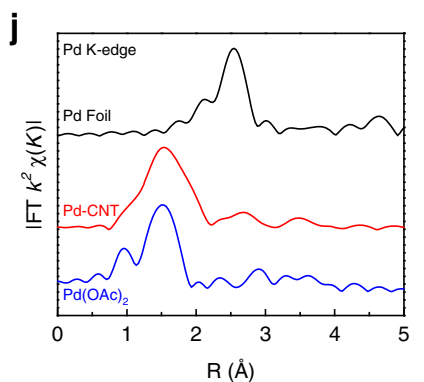

C

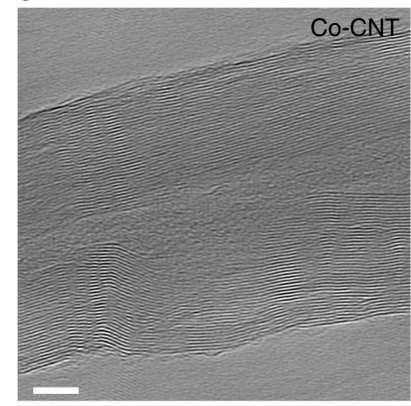

g
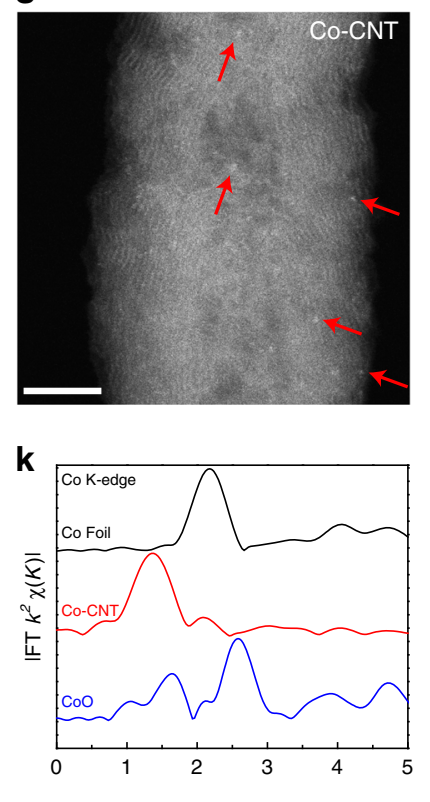

d

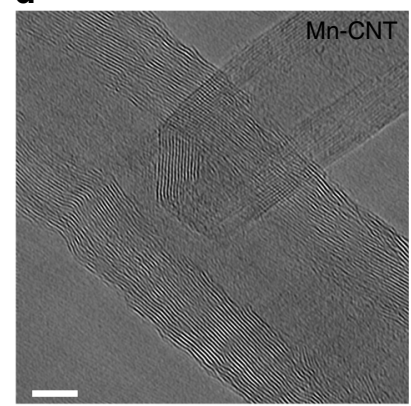

h

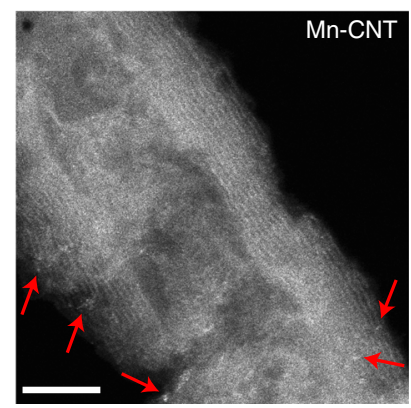

I

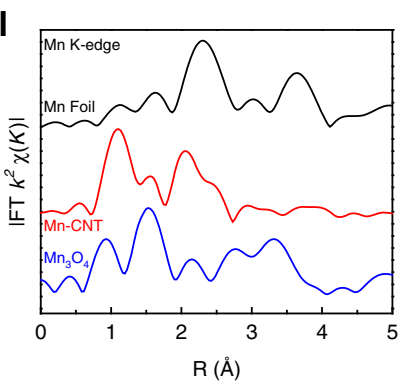

Fig. 1 TEM and XAS characterizations of M-CNT catalysts. High resolution TEM and aberration-corrected HAADF-STEM images of a, e Fe-, b, $\mathbf{f}$ Pd-,

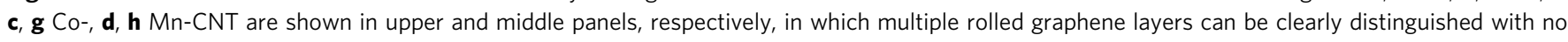
metal clusters/particles observed in each sample. The bright dots in HAADF-STEM (marked by red arrows) represent some typical metal single atoms.

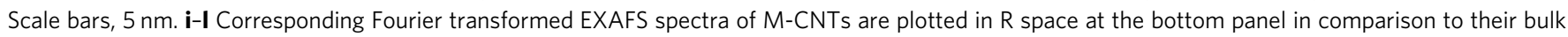
metal foil and metal oxide control samples

"sandwich" approach for the sample tip preparation (Fig. 2). We drop-casted dispersed Fe-CNT onto a nickel-coated substrate, sandwiched in between two 25-nm gold layers deposited by sputter-coating; the gold serves as a marker for the original surface of the CNT powder (Fig. 2a, Supplementary Fig. 11). The $\mathrm{Au}-\mathrm{CNT}-\mathrm{Au}$ sandwich is itself enclosed in layers of sputterdeposited $\mathrm{Ni}$, to give sufficient material supports for APT tip preparation. Focused ion beam (FIB) procedures are applied to cut the sample into pieces, with a corresponding cross-section structure shown in the SEM image of Fig. 2b. Preparation of an APT-compatible needle-shaped specimen is carried out by FIB as shown in Fig. 2c. APT was then performed on a Cameca LEAP $4000 \mathrm{HR}$ as detailed in the Methods, with a total of 9 million atoms collected. The reconstructed tomography of the sample tip is presented in Supplementary Movie 1, with the projected 2D image shown in Fig. 2d. Each dot represents the position of the ion detected by mass spectrometry, with a maximum detection efficiency of $38 \%$ (reflectron atom probe). Au layer as a marker in yellow is observed in the upper left corner, indicating the catalyst region for analysis. A few hundreds of isolated ${ }^{56} \mathrm{Fe}$ atoms (identified only from the $56 \mathrm{Da}$ peak due to molecular fragment overlaps at the other Fe isotopes and charge states) were well dispersed across the sample tip and highlighted in green. A smaller region attached to the Au marker was selected for detailed analysis as shown by the $2 \mathrm{D}$ contour map of carbon atom distribution (Fig. 2e), where the shape of a CNT was resolved. Fe atoms were distributed uniformly along the CNT as shown in the corresponding $2 \mathrm{D}$ projection (Fig. 2f), with no neighboring $\mathrm{Fe}$ atoms observed with a distance less than $3 \AA$. This is in consistent with STEM and XAS characterizations and further confirms the atomic dispersion of $\mathrm{Fe}$ in CNT. While a closer observation around $\mathrm{Fe}$ atoms is not able to provide the exact atomic structures due to the loss of ion signals during the detection process as well as the APT resolution $(0.1-0.3 \mathrm{~nm})$, it could still give us important hints of the possible coordination environment: the side view suggests a few atomic layers where Fe single atoms were anchored; the top view of one atomic layer, although with vacant space since a portion of atoms were not detected, shows that the isolated $\mathrm{Fe}$ atoms may have neighboring coordination with both $\mathrm{C}$ and $\mathrm{O}$, suggesting a possible coordination of $\mathrm{Fe}-\mathrm{C}-\mathrm{O}$ motifs which will be further discussed in our theoretical calculations.

Electrocatalytic ORR characterizations. The ORR performances were evaluated in $0.1 \mathrm{M} \mathrm{KOH}$ by casting a thin catalyst layer onto rotation ring disk electrode (RRDE), with the collection efficiency 
a

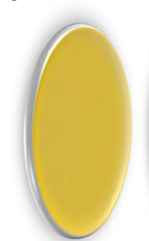

Sil $/ \mathrm{Au}_{100} \mathrm{~nm} \quad \mathrm{Ni} \mathrm{H}_{100 \mathrm{~nm}} \mathrm{AU}_{25} \mathrm{~nm}$ Fe-CNT

"Sandwich" nanofabrication



$\mathrm{Ni}_{350 \mathrm{~mm}}$

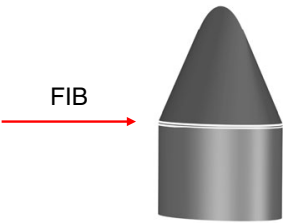

Sample tip



Atom probe tomography b

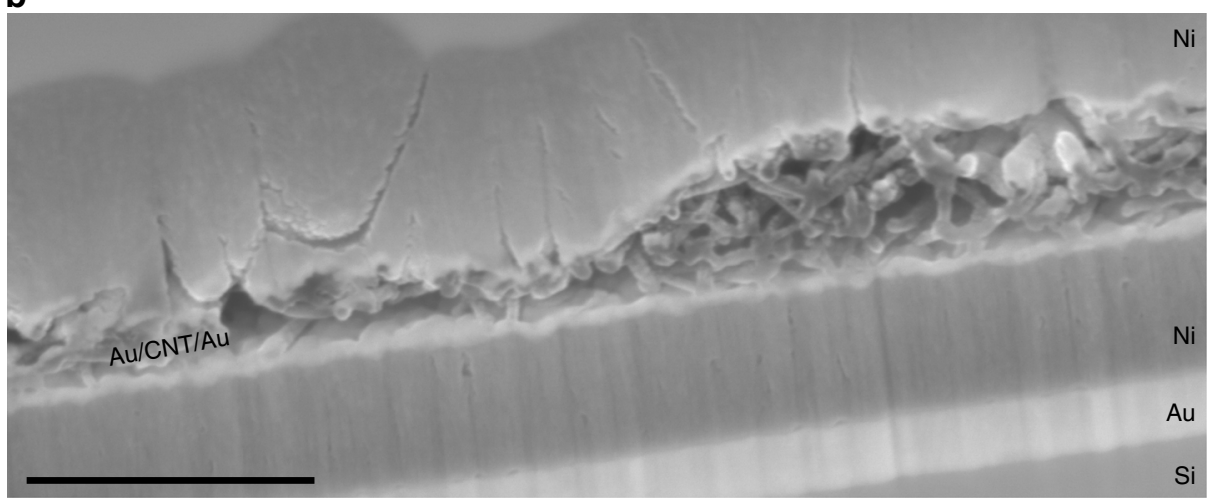

c

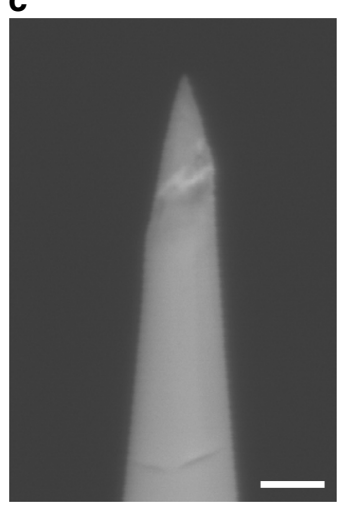

d

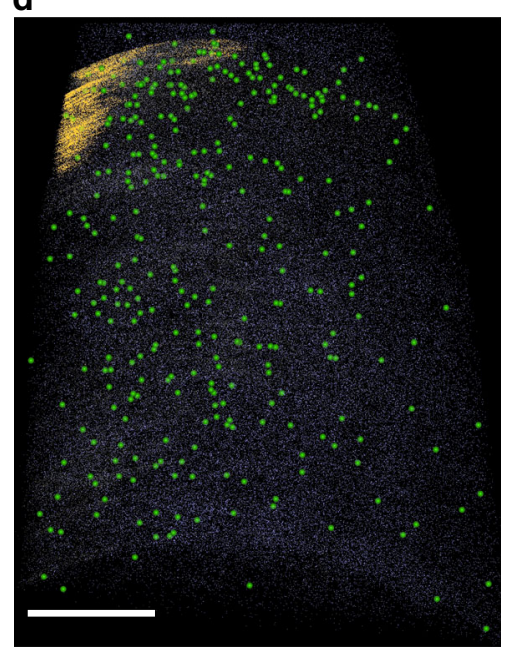

e

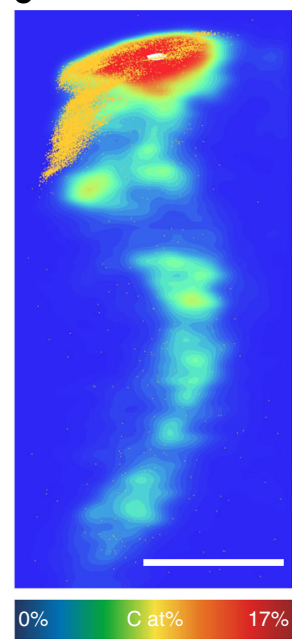

f

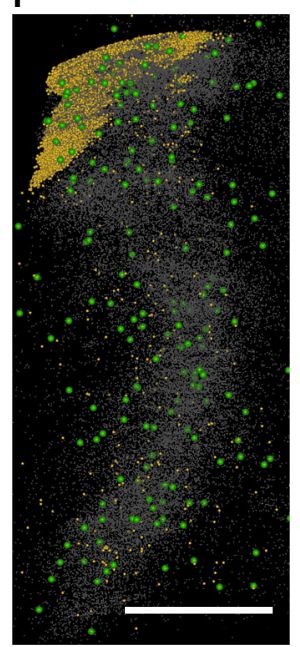

g
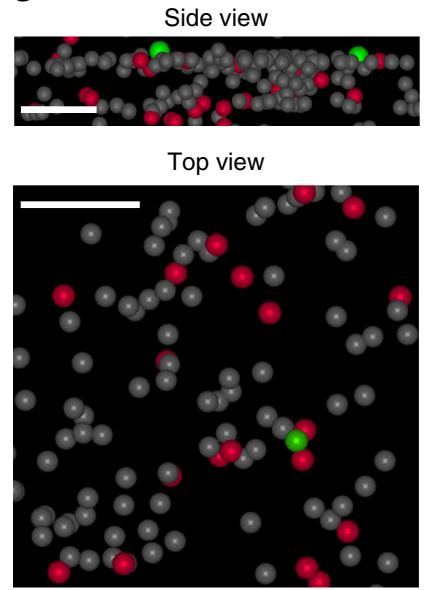

Au $\mathrm{Fe} O \mathrm{C} \quad \mathrm{OO}$

Fig. 2 Atom probe tomography of Fe-CNT catalyst. a The schematic of the nanofabrication procedure of APT sample tips. $\mathbf{b}$ The cross-section SEM image of a catalyst sandwich after FIB cutting. c SEM image of the final APT specimen tip anchored on a Si microtip after sharpening. $\mathbf{d}$ Reconstructed APT data for a region containing Fe-CNT, with (e) a $2 \mathrm{D}$ contour plot of $\mathrm{C}$ atomic concentration and $\mathbf{f}$ the corresponding reconstruction for a region of $40 \times 40 \times 80$ $\mathrm{nm}$ surrounding a CNT. $\mathbf{g}$ Side and top view of CNT planes, where single Fe atoms may have direct coordination with both $\mathrm{C}$ and $\mathrm{O}$. The vacant space is mainly due to the low detection efficiency of atoms. Atom labels, Au in yellow, Fe in green, C in gray, and O in red in $\mathbf{d}-\mathbf{g}$; Scale bars, $500 \mathrm{~nm}$ in $\mathbf{b}, 200 \mathrm{~nm}$ in $\mathbf{c}, 20 \mathrm{~nm}$ in $\mathbf{d}-\mathbf{f}$, and $2 \mathrm{~nm}$ in $\mathbf{g}$

pre-calibrated by the redox reaction of $\left[\mathrm{Fe}\left(\mathrm{CN}_{6}\right)\right]_{4}-/\left[\mathrm{Fe}\left(\mathrm{CN}_{6}\right)\right]_{3}{ }^{-}$ (Supplementary Fig. 12, Methods). The potential of reference electrode was double confirmed by purging pure $\mathrm{H}_{2}$ gas onto a physically and electrochemically polished polycrystalline Pt wire or Pt rotation disc electrode at a reasonable rotation speed (Supplementary Fig. 13, Methods). The ORR peak of Fe-CNT was observed in the cyclic voltammetry in $\mathrm{O}_{2}$-saturated electrolyte, in contrast with the double layer current when $\mathrm{O}_{2}$ was switched to $\mathrm{N}_{2}$ (Supplementary Fig. 14). Figure 3a shows the polarization curves of M-CNTs for their performance screening at a constant catalyst loading of $0.1 \mathrm{mg} \mathrm{cm}^{-2}$, together with the $\mathrm{H}_{2} \mathrm{O}_{2}$ generation current detected by the Pt ring electrode (Methods). Note that the possible $\mathrm{H}_{2} \mathrm{O}_{2}$ decomposition on metal oxides compared to the generation should be negligible (Supplementary Note 3). The corresponding $\mathrm{H}_{2} \mathrm{O}_{2}$ selectivity and electron transfer numbers were plotted in Fig. $3 \mathrm{~b}$ as a function of potential. The background performance of CNT support (O content of 4.5\%) showed similar $\mathrm{H}_{2} \mathrm{O}_{2}$ selectivity compared to previous studies (Fig. 3a, b $)^{27}$, which was significantly improved or decreased with TM single atoms incorporated. Note that the O contents in CNT were barely changed after the doping of metal atoms (Supplementary Fig. 8), ruling out its contribution to the changes of $\mathrm{H}_{2} \mathrm{O}_{2}$ selectivity. In addition, we excluded the possibility that the ratio between $\mathrm{C}$ and $\mathrm{O}$ might be influenced by adsorbed carbon dioxide and oxygen gas from air (Supplementary Fig. 15). Among those different TMs, Fe-CNT presents the best $\mathrm{H}_{2} \mathrm{O}_{2}$ generation 
a

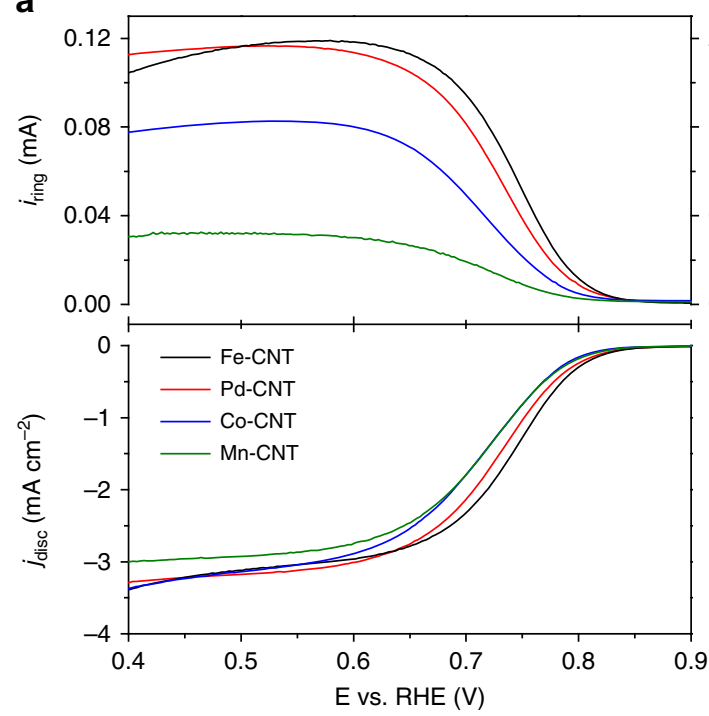

2.537

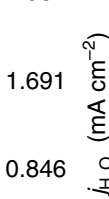

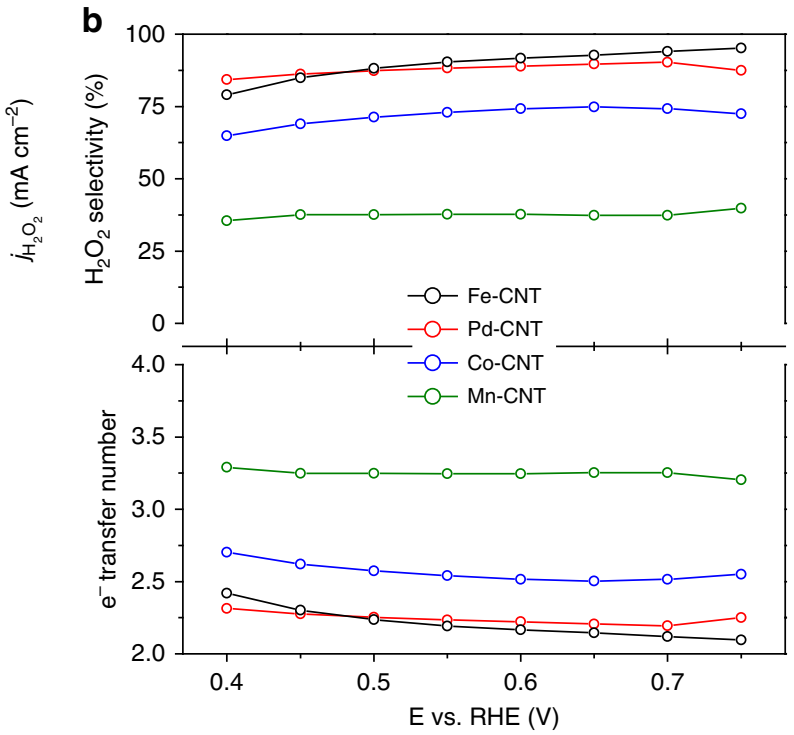

C



d





e

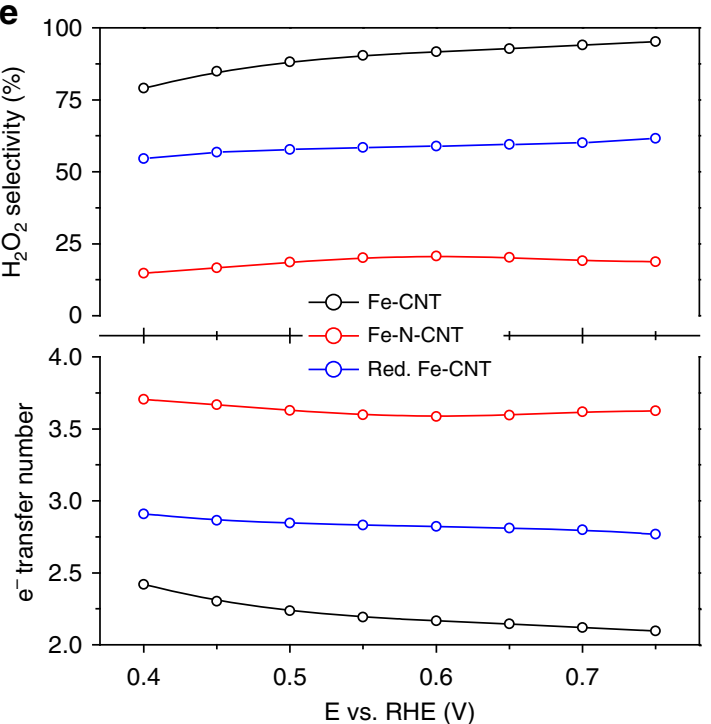

Fig. 3 ORR performance of M-CNT catalysts cast RRDE in 0.1 M KOH. a Linear sweep voltammetry (LSV) of CNT background and Fe-, Pd-, Co-, Mn-CNT catalysts recorded at $1600 \mathrm{rpm}$ and a scan rate of $5 \mathrm{mV} \mathrm{s}^{-1}$, together with the detected $\mathrm{H}_{2} \mathrm{O}_{2}$ currents on the ring electrode (upper panel) at a fixed potential of $1.2 \mathrm{~V}$ vs. RHE. b Calculated $\mathrm{H}_{2} \mathrm{O}_{2}$ selectivity and electron transfer number during potential sweep. c Stability measurement of Fe-CNT at a fixed disk potential of $\sim 0.71 \mathrm{~V}$. The ring electrode was refreshed several times by rapid scan at negative potentials to remove the accumulated $\mathrm{PtO}_{\mathrm{x}}$ in continuous operation. d, e LSV and corresponding $\mathrm{H}_{2} \mathrm{O}_{2}$ selectivity comparison on Fe-CNT, Fe-N-CNT, and forming gas reduced Fe-CNT (Red. Fe-CNT) catalysts 
performance evaluated by RRDE, with a maximal $\mathrm{H}_{2} \mathrm{O}_{2}$ selectivity of more than $95 \%$, and a high potential of $0.822 \mathrm{~V} v s$. RHE to deliver a $0.1 \mathrm{~mA} \mathrm{~cm}{ }^{-2} \mathrm{H}_{2} \mathrm{O}_{2}$ onset current. This early onset is superior to the so-far reported $\mathrm{H}_{2} \mathrm{O}_{2}$ catalysts as listed in the performance chart (Supplementary Fig. 16) ${ }^{5,18,22-25}$, such as Pd$\mathrm{Hg}(0.72 \mathrm{~V})^{15}, \mathrm{Au}-\mathrm{Pd}(0.54 \mathrm{~V})^{17}$, Pt single atoms $(0.71 \mathrm{~V})^{16}$, and highly oxidized CNTs $(0.75 \mathrm{~V})^{27}$, representing a facile ORR kinetics with negligible overpotential for $\mathrm{O}_{2}$-to- $\mathrm{H}_{2} \mathrm{O}_{2}$ conversion $5,19,23-26]$. By switching the metal dopants from $\mathrm{Fe}$ to $\mathrm{Pd}$, Co, and $\mathrm{Mn}$, the $\mathrm{H}_{2} \mathrm{O}_{2}$ selectivity was changed to $90.3,74.8$, and $39.8 \%$, respectively, suggesting a wide range tuning of electron transfer numbers from 2.09 to 3.20. Supplementary Figure 17 shows the effects of Fe atom loading $(0,0.05,0.1$, and 0.2 at $\%)$ on $\mathrm{H}_{2} \mathrm{O}_{2}$ activity and selectivity. Compared to bare CNT, the performance was gradually increased with the increase of Fe atom loading, but dramatically dropped once Fe clusters was formed (Supplementary Note 1 and Supplementary Fig. 2), demonstrating the critical role of atomically dispersed Fe. Fe-CNT maintains its high $\mathrm{H}_{2} \mathrm{O}_{2}$ selectivity and activity when applied onto a GDL electrode with facilitated $\mathrm{O}_{2}$ mass diffusion for large current densities in electrolyzer, where the colorimetric quantification of $\mathrm{H}_{2} \mathrm{O}_{2}$ was employed instead (Supplementary Fig. 18, Methods). In $1 \mathrm{M} \mathrm{KOH}$, the catalyst delivered a steady-state $\mathrm{H}_{2} \mathrm{O}_{2}$ partial current of $43 \mathrm{~mA} \mathrm{~cm}^{-2}$ at $0.76 \mathrm{~V}$ with a Faradaic efficiency of $95.4 \%$, corresponding to a $\mathrm{H}_{2} \mathrm{O}_{2}$ production rate of $\sim 1.6 \mathrm{~mol} \mathrm{~g}^{-1} \mathrm{~h}^{-1}$ or $8 \mathrm{~mol} \mathrm{~m}^{-2} \mathrm{~h}^{-1}$ (Supplementary Fig. 19). The catalytic activity of Fe-CNT in both RRDE test and bulk electrolysis presents significant improvements compared to previous studies of oxidized carbon catalysts (Supplementary Fig. 20). The performance stability of Fe-CNT single atom catalyst was also demonstrated on RRDE in Fig. 3c, with a stable $\mathrm{H}_{2} \mathrm{O}_{2}$ selectivity of above $90 \%$ over the 8-h continuous operation (Methods). Post-catalysis XAS analysis of Fe K-edge XANES overlaps well with that of pristine $\mathrm{Fe}-\mathrm{CNT}$, suggesting that the electronic structure and coordination of Fe single atoms remains unchanged (Supplementary Fig. 21). The corresponding Fourier transformed EXAFS spectrum of post-catalysis $\mathrm{Fe}-\mathrm{CNT}$ reveals that $\mathrm{Fe}$ atoms still maintain an atomic dispersion. The reaction pathway can also be tuned by maintaining the metal center while switching its neighboring metalloid coordination, which combined with the corresponding changes in catalytic performances could further reveal the possible active coordination motifs for $\mathrm{H}_{2} \mathrm{O}_{2}$ generation. The $\mathrm{H}_{2} \mathrm{O}_{2}$ selectivity of Fe-CNT was significantly decreased to a maximum of $60 \%$ when the catalyst was annealed in forming gas with $\mathrm{Fe}-\mathrm{C}-\mathrm{O}$ coordination reduced (Red. Fe-CNT); the $4 \mathrm{e}^{-}$ORR pathway was preferred when $\mathrm{O}$ was replaced with $\mathrm{N}$ to form $\mathrm{Fe}-\mathrm{C}-\mathrm{N}$ coordination, with the electron transfer number boosted from 2.09 of Fe-CNT to 3.71 of Fe-N-CNT ${ }^{13,49-52}$, and even to 3.90 when the mass loading was increased to a typical fuel cell test condition (Supplementary Fig. 22) ${ }^{13,53}$.

Theoretical calculations. The above experiments suggested that the product selectivity of ORR could be related with the coordination motifs of $\mathrm{Fe}-\mathrm{C}-\mathrm{O}$ or $\mathrm{Fe}-\mathrm{C}-\mathrm{N}$ in those single atom catalysts. While based on current experimental techniques it is still challenging to directly resolve all of the exact atomic structures, density functional theory (DFT) calculations of different configurations (a total of 18 configurations as shown in Fig. 4a) become of great importance to understand the origin of selectivity change, and for rational design of new catalysts in the future. We used a two-dimensional graphene to model the CNT support used here, since the difference in binding free energies of reaction intermediates at CNT with a diameter larger than $20 \mathrm{~nm}$ and at the two-dimensional graphene is $<0.1 \mathrm{eV}^{54}$. We considered carbon vacancies up to six, tested all the possible sites of metal atom


b


Fig. 4 DFT calculations of the ORR activity and selectivity on different motifs. a All examined configurations for single Fe atom coordinated in twodimensional carbon material with and without $O$ species. We used the most stable surface coverage as a reference (Supplementary Figs. 29-31). Green, red, and gray colors denote Fe, $\mathrm{O}$ (or $\mathrm{N}$ ), and $\mathrm{C}$ atoms, respectively. $\mathbf{b}$ The calculated ORR activity volcano plot for $2 \mathrm{e}^{-}$pathway to $\mathrm{H}_{2} \mathrm{O}_{2}$. Red and blue symbols indicate ${ }^{\star} \mathrm{OOH}$ adsorption at $\mathrm{C}$ and $\mathrm{Fe}$, respectively. The equilibrium potential of $\mathrm{O}_{2} / \mathrm{H}_{2} \mathrm{O}_{2}$ is shown as a black dashed line. Some of the points are not shown in the volcano plot since their binding energies are out of the range

binding, and selected the most stable configurations. Representative formation energies (Supplementary Note 4) of single atom configurations and surface adsorption of metal atoms suggest that the metal single atoms prefer to chemically bind with $\mathrm{C}$ and $\mathrm{O}$ in $\mathrm{CNT}$ vacancies, forming stable $\mathrm{M}-\mathrm{C}-\mathrm{O}$ configurations other than being simply adsorbed on CNT (Supplementary Table 2, Supplementary Fig. 23). In addition, the effects of $\mathrm{O}$ and $\mathrm{N}$ were carefully investigated. As a prototypical system, we investigated $\mathrm{Fe}$ doped system, which was found to be the most active and selective for $\mathrm{H}_{2} \mathrm{O}_{2}$ production in the experiments.

It has been shown in the past that the oxygen reduction catalytic activity and selectivity can be related to the binding free energies of reaction intermediates ${ }^{4,5,27-29}$. In the $2 \mathrm{e}^{-}$reduction of $\mathrm{O}_{2}$ to $\mathrm{H}_{2} \mathrm{O}_{2}\left(\mathrm{H}_{2} \mathrm{O}_{2}\right.$ in $\mathrm{pH}<11.6$ or its deprotonated anion but 
a


e


Fig. 5 Disinfection performance of Fe-CNT in neutral $\mathrm{pH}$. a Schematic of electrochemical synthesis of $\mathrm{H}_{2} \mathrm{O}_{2}$ for water disinfection, with green inputs such as sunlight, air, and water. b, c LSV of Fe-CNT catalyst on RRDE at 1600 rpm in $0.1 \mathrm{M} \mathrm{PBS} \mathrm{(pH} \mathrm{7.2)} \mathrm{with} \mathrm{the} \mathrm{corresponding} \mathrm{H}_{2} \mathrm{O}_{2}$ selectivity under different potentials. d LSV of Fe-CNT catalyst on GDL electrode $\left(0.5 \mathrm{mg} \mathrm{cm}^{-2}\right.$ mass loading) in an $\mathrm{H}$-cell electrolyzer. e Bulk electrolysis at a constant current density of $20 \mathrm{~mA} \mathrm{~cm}^{-2}$ in $0.1 \mathrm{M}$ PBS containing $\sim 10^{7}$ c.f.u. $\mathrm{mL}^{-1} \mathrm{E}$ coli bacteria. The $\mathrm{H}_{2} \mathrm{O}_{2}$ concentration of 1613 ppm at 210 min was determined from a bacteria-free control experiment. $\mathbf{f}$ CCD photos of overnight cultured plates with spread droplets taken from different time slots during the electrolysis. Dilution factor is labeled at the right bottom corner of each image. No bacteria colonies were observed after 2-h treatment. $\mathbf{g}$ The disinfection efficiency as a function of treatment time. The error bar represents two identical cultured plates 
$\mathrm{HO}_{2}^{-}$in $\mathrm{pH}>11.6$ ), the catalytic activity can be determined by the binding strength of the key reaction intermediate, ${ }^{\star} \mathrm{OOH}$. For the catalysts with weak tendency toward ${ }^{\star} \mathrm{OOH}$ adsorption, $\mathrm{O}_{2}$ activation (Eq. 1) is the potential limiting step (PDS), while desorption of ${ }^{\star} \mathrm{OOH}$ (Eqs. 2.1 and 2.2) is the PDS for strongly ${ }^{\star} \mathrm{OOH}$ binding catalysts.

$$
\begin{gathered}
\mathrm{O}_{2}+\mathrm{H}_{2} \mathrm{O}+e^{-} \rightarrow * \mathrm{OOH}+\mathrm{OH}^{-} \\
* \mathrm{OOH}+e^{-} \rightarrow *+\mathrm{HO}_{2}^{-} \quad(\mathrm{pH}>11.6) \text { or } \\
* \mathrm{OOH}+\mathrm{H}_{2} \mathrm{O}+e^{-} \rightarrow *+\mathrm{H}_{2} \mathrm{O}_{2}+\mathrm{OH}^{-}(\mathrm{pH}<11.6)
\end{gathered}
$$

We therefore use $\Delta \mathrm{G}_{{ }^{*} \mathrm{OOH}}$ as a descriptor to estimate the limiting potential $\left(\mathrm{U}_{\mathrm{L}}\right)$ of $\mathrm{O}_{2}$ reduction to $\mathrm{H}_{2} \mathrm{O}_{2}$. The maximum $U_{\mathrm{L}}$, i.e., zero overpotential at the top of the volcano, is $0.68 \mathrm{~V}$ vs. RHE originated from the experimental formation free energies of $\mathrm{H}_{2} \mathrm{O}_{2}$. There is a small difference in the formation free energy of its deprotonated anion of $\mathrm{HO}_{2}^{-}$, shifting the equilibrium potential positively by $70 \mathrm{mV}$ to $0.75 \mathrm{~V}$ vs. RHE in alkaline solutions with $\mathrm{pH}$ higher than 11.6. We note that an onset potential around 0.8 $\mathrm{V}$, which is higher than the thermodynamic potential of $0.75 \mathrm{~V}$, was observed in our experimental results. This phenomenon has been reported in previous studies ${ }^{5,26-28,55}$. The main driving force for such difference has been suggested to be the Nernstrelated potential shift due to the low concentration of $\mathrm{H}_{2} \mathrm{O}_{2}$ in the electrolyte. We present the volcano plots in the form of $\mathrm{H}_{2} \mathrm{O}_{2}$ with the $0.68 \mathrm{~V}$ equilibrium potential throughout this work unless stated otherwise to represent a wider $\mathrm{pH}$ range for general mechanism understanding. It should be noted that catalysts positioned at the left leg of the volcano plot are expected to be less selective toward $\mathrm{H}_{2} \mathrm{O}_{2}$. This is due to their strong ${ }^{\star} \mathrm{OOH}$ adsorption energy, which favors dissociating the $\mathrm{O}-\mathrm{O}$ bond and driving the $4 \mathrm{e}^{-}$pathway with $\mathrm{H}_{2} \mathrm{O}$ as the major product ${ }^{5,27-29}$. Our results show that in the examined $\mathrm{Fe}-\mathrm{C}$ systems without $\mathrm{O}$, $\mathrm{Fe}$, and the $\mathrm{C}$ atoms around $\mathrm{Fe}$ present $\mathrm{U}_{\mathrm{L}}$ much smaller than $0.68 \mathrm{~V}$ and therefore do not contribute to the ORR activity (Supplementary Fig. 24). Once oxygen is included into the systems, most of the $\mathrm{C}$ atoms in the vicinity of the $\mathrm{Fe}-\mathrm{C}-\mathrm{O}$ motif (Fig. 4b) show very high activity for $\mathrm{H}_{2} \mathrm{O}_{2}$ production and are positioned near the top of the volcano. The fact that most of the $\mathrm{C}$ sites are mainly located at the right leg of the volcano, implies that the $\mathrm{C}$ atoms of $\mathrm{Fe}-\mathrm{C}-\mathrm{O}$ motifs could also be selective for $2 \mathrm{e}^{-}$ product of $\mathrm{H}_{2} \mathrm{O}_{2}$ over $4 \mathrm{e}^{-}$to $\mathrm{H}_{2} \mathrm{O}$. This trend remains valid in strong alkaline solutions with the formation of $\mathrm{HO}_{2}^{-}$as shown in Supplementary Fig. 25, as in the theoretical model the difference in the equilibrium potential only results in the change of the peak position by $0.07 \mathrm{eV}$. In addition, we found out that the incorporation of $\mathrm{Fe}$ atoms in $\mathrm{Fe}-\mathrm{C}-\mathrm{O}$ motifs, compared to those with only $\mathrm{O}$ dopants, can generally strengthen the ${ }^{\star} \mathrm{OOH}$ binding on $\mathrm{C}$ sites (Supplementary Fig. 26). This as a result significantly improves the $\mathrm{H}_{2} \mathrm{O}_{2}$ activity towards the top of the volcano, suggesting the critical roles of both $\mathrm{Fe}$ and $\mathrm{O}$ atoms in the coordination. We also calculated the ORR activity of Fe sites in different $\mathrm{Fe}-\mathrm{C}-\mathrm{O}$ model systems, and realized that those $\mathrm{Fe}$ sites generally bind the ${ }^{*} \mathrm{OOH}$ too strongly, resulting in $\mathrm{O}-\mathrm{O}$ bond dissociation (Fig. 4b). The calculated $U_{\mathrm{L}} s$ of the Fe in variety of $\mathrm{Fe}-\mathrm{C}-\mathrm{O}$ are $<0.3 \mathrm{~V}$, indicating a very low $\mathrm{ORR}$ activity. Therefore, we suspect that the $\mathrm{C}$ site in $\mathrm{Fe}-\mathrm{C}-\mathrm{O}$ motif is where $\mathrm{O}_{2}$ gets selectively reduced to $\mathrm{H}_{2} \mathrm{O}_{2}$. This is in consistent with our in-Operando XANES spectra where the oxidation state of $\mathrm{Fe}$ remained unshifted, suggesting no additional $\mathrm{Fe}-\mathrm{O}$ bonding formed during the reaction conditions (Supplementary Fig. 27).

To investigate the effect of local coordination environment on selectivity, we also modeled variety of $\mathrm{Fe}-\mathrm{C}-\mathrm{N}$ configurations, where $\mathrm{O}$ atoms are replaced by $\mathrm{N}$ (Supplementary Fig. 24c). Our results show that the $\mathrm{Fe}$ sites in all the $\mathrm{Fe}-\mathrm{C}-\mathrm{N}$ motifs are rather active for ORR to $\mathrm{H}_{2} \mathrm{O}$ with ${ }^{\star} \mathrm{OOH}$ adsorption energies positioned in the range of interests for $4 \mathrm{e}^{-}$pathway 4 . This is in a very good agreement with our experimental results as well as previous literature, that $\mathrm{Fe}-\mathrm{C}-\mathrm{N}$ system is highly active for ORR in fuel cell applications ${ }^{13,56}$. Contrary to the $\mathrm{Fe}-\mathrm{C}-\mathrm{O}$ coordination, $\mathrm{C}$ sites of $\mathrm{Fe}-\mathrm{C}-\mathrm{N}$ system bind ${ }^{\star} \mathrm{OOH}$ very weakly (Supplementary Fig. 24c), indicating that $\mathrm{C}$ sites are not active for $2 \mathrm{e}^{-}$nor $4 \mathrm{e}^{-}$ORR processes. The Fe active site in $\mathrm{Fe}-\mathrm{N}-\mathrm{CNT}$ was again confirmed by our in-Operando XANES experiment that, the oxidation state of Fe was slightly increased due to new $\mathrm{Fe}-\mathrm{O}$ bonds formed under reaction conditions (Supplementary Fig. 27 $)^{50,57-59}$. Additional calculations of different M-C-O motifs in M-CNT catalysts as well as CNT support were presented by volcano plots in Supplementary Fig. 28, where the general trend of $\mathrm{H}_{2} \mathrm{O}_{2}$ selectivity matches with our experimental results.

Water disinfection by Fe-CNT catalyst. A wide range of practical applications could be realized with this low-cost Fe-CNT catalyst for highly efficient $\mathrm{H}_{2} \mathrm{O}_{2}$ generation. Since $\mathrm{H}_{2} \mathrm{O}_{2}$ has been widely used in killing bacteria ${ }^{60}$, one promising field is the delocalized or green-route water disinfection with accessible inputs including sunlight for electricity, air for $\mathrm{O}_{2}$, and water as shown in the schematic in Fig. 5a. Here we performed a prototype experiment to test the catalyst's disinfection effectiveness. Neutral $\mathrm{pH}$ needs to be used instead of alkaline solutions to mimic the practical applications, therefore the ORR selectivity of Fe-CNT was first evaluated in 0.1 M PBS electrolyte using RRDE as shown in Figs. $5 b$ and $5 c . \mathrm{H}_{2} \mathrm{O}_{2}$ generation starts at $\sim 0.53 \mathrm{~V}$ and maintains a high selectivity above $90 \%$ from 0.5 to $0.3 \mathrm{~V}$. The practical electrolysis was performed in an $\mathrm{H}$-cell where $\mathrm{Fe}-\mathrm{CNT}$ catalyst was casted onto a GDL electrode $\left(0.5 \mathrm{mg} \mathrm{cm}^{-2}\right.$ catalyst loading), with the catalytic performance plotted in Fig. 5d. The potential to deliver a $20 \mathrm{~mA} \mathrm{~cm}^{-2}$ constant current for $\mathrm{H}_{2} \mathrm{O}_{2}$ generation remained unchanged over the course of electrolysis (Fig. 5e). Around 1613 ppm $\mathrm{H}_{2} \mathrm{O}_{2}$ was generated within $210 \mathrm{~min}$ electrolysis as determined by the colorimetric quantification method, representing an average Faradaic Efficiency of $90.8 \%$. With those performance metrics obtained, electrolyte with Escherichia coli (E. coli) was then used as a model system at a bacteria concentration of $\sim 10^{7}$ colony forming units (c.f.u.) $\mathrm{mL}^{-1}$. The disinfection process was monitored by picking up several droplets during the $20 \mathrm{~mA} \mathrm{~cm}^{-2}$ chronopotentiometric measurement, followed by serially dilution and spread plating onto LB agar for overnight culture ${ }^{61,62}$. The dark-field CCD images of agar plates with cultured bacteria colony are shown in Fig. 5f, with the calculated killing rate plotted in Fig. 5g. Fe-CNT demonstrates a rapid disinfection efficiency for $E$. coli, delivering a $43 \%$ bacteria inactivation in $5 \mathrm{~min}$ and more than $99.9999 \%$ in $120 \mathrm{~min}$ (equals to a $125 \mathrm{~L} \mathrm{~h}^{-1} \mathrm{~m}^{2}$ electrode processing rate) with no recovery observed (Supplementary Fig. 32). We further suspended $E$ coli bacteria into 2-h electrolyzed 0.1 M PBS solution (ca. 1000 ppm of generated $\mathrm{H}_{2} \mathrm{O}_{2}$ concentration) with the image of overnight cultured plate shown in Supplementary Fig. 29, which clearly excludes any effects of disinfection from applied potential. This device can be further upgraded into a flow cell with tunable water flow rate and current density for a wellbalanced water disinfection rate and efficiency for specific applications in the future.

\section{Discussion}

Our experimental and theoretical results highlight that the TM single atom coordination motifs can effectively tune the ORR pathways and product selectivity. Among different catalysts examined, $\mathrm{Fe}-\mathrm{C}-\mathrm{O}$ coordination was identified as highly active and selective motif for $\mathrm{O}_{2}$ reduction to $\mathrm{H}_{2} \mathrm{O}_{2}$. Given the many 
choices of TM atoms, supports, as well as non-metal dopants, this wide range of coordination combinations could enrich the pool of catalytic active sites for improving, controlling, and understanding catalytic reactions beyond ORR. Future efforts also could be focused on electrolysis cell design for pure $\mathrm{H}_{2} \mathrm{O}_{2}$ solution generation without solute mixtures. In addition, by integrating renewable electricity from solar or wind with water and air, our earth-abundant Fe-CNT $\mathrm{H}_{2} \mathrm{O}_{2}$ catalyst could therefore pave a green way, different from the traditional anthraquinone process, for $\mathrm{H}_{2} \mathrm{O}_{2}$ generation, water treatment, chemical synthesis, and many other important applications in the future.

\section{Methods}

Material synthesis and characterization. M-CNT catalysts were prepared by the impregnation and reduction method. In a typical synthesis of Fe-CNT, a 7.5-mM iron nitrate stock solution was first prepared by dissolving $\mathrm{Fe}\left(\mathrm{NO}_{3}\right)_{3} \cdot 9 \mathrm{H}_{2} \mathrm{O}$ (ACS Grade, Alfa Aesar) into Millipore water $(18.2 \mathrm{M} \Omega \cdot \mathrm{cm})$. A carbon suspension was prepared by mixing $50 \mathrm{mg}$ multi-walled carbon nanotubes (Carbon Nanotubes Plus GCM389, used as received) with $20 \mathrm{~mL}$ of Millipore water, and tip sonicated (Branson Digital Sonifier) for $30 \mathrm{~min}$ till a homogeneous dispersion. Then $200 \mu \mathrm{L}$ of $\mathrm{Fe}^{2+}$ solution, given a raw atomic ratio of $\mathrm{Fe}: \mathrm{C}$ to be $\sim 0.1$ at.\%, was dropwise added into CNT solution under vigorous stirring, followed by a quickly frozen in liquid nitrogen. The as-prepared $\mathrm{Fe}\left(\mathrm{NO}_{3}\right)_{3} / \mathrm{CNT}$ powder was heated up in a tube furnace to $600^{\circ} \mathrm{C}$ at a pressure of 1 Tor and a gas flow of $100 \mathrm{sccm}$ Ar (UHP, Airgas) within $20 \mathrm{~min}$, and kept at same temperature for another $40 \mathrm{~min}$ before cooling down to room temperature. Other Pd-, Co-, and $\mathrm{Mn}-\mathrm{CNT}$ s were prepared in a similar way to $\mathrm{Fe}-\mathrm{CNT}$ except for various metal salt precursors, i.e., $\mathrm{Pd}$ $\left(\mathrm{NO}_{3}\right)_{2} \cdot 2 \mathrm{H}_{2} \mathrm{O}, \mathrm{Co}\left(\mathrm{NO}_{3}\right)_{2} \cdot 6 \mathrm{H}_{2} \mathrm{O}$, and $\mathrm{Mn}\left(\mathrm{NO}_{3}\right)_{2} \cdot 4 \mathrm{H}_{2} \mathrm{O}$ (Puriss or ACS Grade, Sigma-Aldrich), respectively. $\mathrm{N}$ doped $\mathrm{Fe}-\mathrm{N}-\mathrm{CNT}$ was prepared by heating up the above-mentioned $\mathrm{Fe}\left(\mathrm{NO}_{3}\right)_{3} / \mathrm{CNT}$ powder under a same temperature program with Fe-CNT but within a mixed gas flow of $50 \mathrm{sccm} \mathrm{NH}_{3}$ (anhydrous, Airgas) + $100 \mathrm{sccm}$ Ar.

Probe-corrected FEI Titan Themis 300 S/TEM with ChemiSTEM technology was used for S/TEM characterization. Drift correction was applied during acquisition. SEM was performed on a Zeiss Supra55VP field emission scanning electron microscope with in-lens detector. X-ray photoelectron spectroscopy was obtained with a Thermo Scientific K-Alpha ESCA spectrometer, using a monochromatic $\mathrm{Al} \mathrm{Ka}$ radiation $(1486.6 \mathrm{eV})$ and a low energy flood gun as neutralizer. Thermo Avantage V5 program were employed for surface componential content analysis.

Ex situ XAS spectra on Co, Mn K-edge were acquired at the SXRMB beamline of Canadian Light Source using a 4-element Si drift fluorescence detector, and Pd $\mathrm{K}$-edge spectra were acquired in fluorescence mode with a 32-element Ge detector at the HXMA beamline. The powder sample was spread onto doublesided, conducting carbon tape. In situ electrochemical XAS measurement on Fe K-edge was carried at Beamline 8-ID, National Synchrotron Light Source II, Brookhaven National Laboratory, using a $\mathrm{Si}(111)$ monochromator and a Lytle detector. For in situ spectroelectrochemical tests, continuous $\mathrm{O}_{2}$ flow was delivered into a homemade Teflon $\mathrm{H}$-cell filled with $\mathrm{O}_{2}$-saturated $0.1 \mathrm{M} \mathrm{KOH}$, a Kapton film covered gas diffusion layer (Fe-CNT/GDL) working electrode was served as the Xray window for synchrotron radiation. Analyses of both the near edge (in energy scale) and extended range (in $R$ space) XAS spectra were performed using Athena software.

Nanofabrication and APT characterization. Specimens for the 3D Atom Probe Tomography were prepared using an FEI Helios 660 Nanolab Dual-Beam FIB/ SEM. Liftout was performed following standard APT sample prep procedures; sharpening of the tips was performed first with an ion beam accelerating voltage of $30 \mathrm{kV}$, and then (for final shaping and cleanup) at $2 \mathrm{kV}$, to produce tips with apices of $\sim 30 \mathrm{~nm}$ diameter. 3D APT was performed using a Cameca LEAP $4000 \mathrm{HR}$ instrument in laser pulsing mode, with the following operating conditions: laser pulse energy of $100 \mathrm{pJ}$ and repetition rate of $100 \mathrm{kHz}$; base temperature of $40 \mathrm{~K}$; detection rate of $0.5 \%$. The dataset shown in the main text consisted of slightly more than $9 \mathrm{M}$ ions, of which the majority were $\mathrm{Ni}$ from the capping layer above the Au-CNT-Au sandwich. No specimens survived to show the lower Au layer, likely due to the high porosity of the CNT powder material. Analysis of that data was performed using Cameca IVAS 3.16.4 software, with reconstructions based on SEM images of the tip profile. Mass spectrum peaks were ranged using the fullwidth-at-one-tenth-maximum method. Only one peak was ranged as Fe, that being the peak at $56 \mathrm{Da}$; no other Fe isotopes could clearly be identified both due to mass overlaps with other species and due to the low number of detected atoms in this peak (sufficiently low that the other Fe isotopes would be expected to be undetectable below the background noise even without mass overlaps). This implies that the stated conclusions about Fe in this system, as determined by APT, represent an upper limit on the possible number and distribution of Fe atoms around the CNT.
Electrochemical measurements. A BioLogic VMP3 work station was employed to record the electrochemical response. Certain amounts of $\mathrm{KOH}$ (Reagent Grade, Sigma-Aldrich) or $\mathrm{K}_{2} \mathrm{HPO}_{4} / \mathrm{KH}_{2} \mathrm{PO}_{4}$ (ACS Grade, Sigma-Aldrich) was dissolved in Millipore water to prepare the $0.1 \mathrm{M}$ electrolyte. The rotation ring disk electrode (RRDE) measurements were run at $25^{\circ} \mathrm{C}$ in a typical three-electrode cell. A platinum foil $(99.99 \%$, Beantown Chemical) and a saturated calomel electrode (SCE, $\mathrm{CH}$ Instruments) were used as the counter and reference electrode, respectively. A RRDE assembly (AFE6R1PTPK, Pine Instruments) consisting of a glassy carbon rotation disk electrode $(\Phi=5.0 \mathrm{~mm})$ and a Pt ring $(\Phi=15.0 \mathrm{~mm})$ was used, with a theoretical collection efficiency of $25 \%$. Experimentally, the apparent collection efficiency $(N)$ was determined to be $24.1 \%$ in the ferrocyanide/ferricyanide half reaction system at a rotation rate between 400 and $2025 \mathrm{rpm}$ (Supplementary Fig. 9) ${ }^{63}$. To prepare M-CNT cast working electrode, typically, $3.3 \mathrm{mg}$ of as-prepared MCNT catalyst was mixed with $1 \mathrm{~mL}$ of ethanol and $10 \mu \mathrm{L}$ of Nafion 117 solution (5 $\%$, Sigma-Aldrich), and sonicated for $20 \mathrm{~min}$ to get a homogeneous catalyst ink. 6 $\mu \mathrm{L}$ of the ink was pipetted onto glassy carbon disk $\left(0.196 \mathrm{~cm}^{2}\right.$ area, $0.1 \mathrm{mg} / \mathrm{cm}^{2}$ mass loading), got vacuum dried prior to usage. As the catalyst can be dispersed very well in ethanol solutions, uniform catalyst coating can be made on the disc electrode without obvious pin holes or uncovered edge. All potentials measured against SCE was converted to the reversible hydrogen electrode (RHE) scale in this work using $\mathrm{E}$ (vs. RHE) $=\mathrm{E}$ (vs. SCE) $+0.244 \mathrm{~V}+0.059^{*} \mathrm{pH}$, where $\mathrm{pH}$ values of electrolytes were determined by Orion 320 PerpHecT LogR Meter (Thermo Scientific, i.e., 13.0 for $0.1 \mathrm{M} \mathrm{KOH}$ and 13.9 for $1 \mathrm{M} \mathrm{KOH})$. This SCE reference electrode was further calibrated to freshly prepared RHE prior to usage (Supplementary Fig. 13), in good agreement with the calculated values. The diffusion limited current of our catalyst is at around $3 \mathrm{~mA} \mathrm{~cm}^{-2}$ and is higher than that of bare glassy carbon, which may due to the low density of active sites on mirror polished glassy carbon electrode. A gradual degradation of ring current was observed during the continuous RRDE stability test, which was mainly due to the surface oxidation of Pt ring electrode constantly operated at high potential $(1.2 \mathrm{~V}$, Fig. 3c) and can be readily recovered by rapid cyclic voltammetry at low potentials to reduce $\mathrm{PtO}_{\mathrm{x}} \cdot \mathrm{H}_{2} \mathrm{O}_{2}$ selectivity was calculated using the following equation: $\mathrm{H}_{2} \mathrm{O}_{2}$ $(\%)=200 \times \frac{I_{\text {Ring }} / N}{I_{\text {Disk }}+I_{\text {Ring }} / N}$, and the electron transfer number $(n)$ at the disk electrode during ORR was calculated using $n=\frac{4\left|I_{\text {Disk }}\right|}{I_{\text {Disk }}+I_{\text {Ring }} / N}$, where $I_{\text {Ring }}$ is the ring current, $I_{\text {Disk }}$ is the disk current and $N$ is the collection efficiency.

Bulk $\mathrm{H}_{2} \mathrm{O}_{2}$ production in $1 \mathrm{M} \mathrm{KOH}$ was carried out in a customized $\mathrm{H}$-cell electrolyzer, with $0.5 \mathrm{mg} \mathrm{cm}^{-2} \mathrm{Fe}-\mathrm{CNT}$ air-brushed onto a $1 \times 2.5 \mathrm{~cm}^{2}$ Freudenberg GDL electrode (Fuel Cell Store) as ORR cathode, with the anode of $0.2 \mathrm{mg} \mathrm{cm}^{-2}$ $\mathrm{IrO}_{2} / \mathrm{GDL}$ for water oxidation. A Fumasep FAA-3-PK-130 anion exchange membrane (Fuel Cell Store) was employed to separate the chambers. $\mathrm{H}_{2} \mathrm{O}_{2}$ concentration was quantified by cerium sulfate titration based colorimetric method $\left(2 \mathrm{Ce}^{4+}+\mathrm{H}_{2} \mathrm{O}_{2} \rightarrow 2 \mathrm{Ce}^{3+}+2 \mathrm{H}^{+}+\mathrm{O}_{2}\right)^{27}$. The $\mathrm{H}_{2} \mathrm{O}_{2}$ concentration-absorbance curve was calibrated by mixing known amount of commercial $\mathrm{H}_{2} \mathrm{O}_{2}$ solution with $1 \mathrm{mM} \mathrm{Ce}\left(\mathrm{SO}_{4}\right)_{2}$. The absorption at $320 \mathrm{~nm}$ wavelength was measured on a Cary 5000 UV-Vis-NIR spectrometer (Agilent) and used to determine the $\mathrm{Ce}^{4+} / \mathrm{H}_{2} \mathrm{O}_{2}$ concentration (Supplementary Fig. 18). To fit the linear range of calibration curve, the electrolyte collected was further diluted by 10 to 100 times in $0.5 \mathrm{M} \mathrm{H}_{2} \mathrm{SO}_{4}$.

Computational details. Density functional theory calculations were performed using the Vienna Ab Initio Simulation Package (VASP) ${ }^{64,65}$. We used BEEF-vdW exchange-correlation functional, which has been shown to accurately describe chemical and physical interactions between adsorbates and graphene ${ }^{66}$. We set an energy cutoff, a convergence criteria for self-consistent iteration and ionic relaxation to be $500 \mathrm{eV}, 10^{-4} \mathrm{eV}$ and $0.05 \mathrm{eV} / \mathrm{A}$, respectively. Bulk graphene unit cell was optimized using $(12 \times 12 \times 1) \mathrm{k}$-points mesh, resulting in $\mathrm{C}$-C distance to be $1.424 \AA$. $(7 \times 7)$ supercell consisting of 98 carbon atoms with $15 \AA$ of a vacuum perpendicular to the graphene plane was employed to model carbon materials, and we considered up to six carbon vacancies. Various sites for a single metal atom adsorption were assessed, and the effects of oxygen or nitrogen near the single metal atom were taken into account as well. For the adsorption calculations, $(2 \times$ $2 \times 1) \mathrm{k}$-points mesh was utilized.

We analyzed ${ }^{\star} \mathrm{OOH}$ adsorption on the catalysts, where the possible catalytic active site is either the single metal or nearby carbon sites. For single atom catalysts, the single metal atom is significantly under-coordinated compared to their bulk counterparts resulting in markedly strong binding of adsorbates, and it is highly likely that the site is pre-occupied by other adsorbates, such as ${ }^{\star} \mathrm{O}$ and ${ }^{\star} \mathrm{OH}$, under the ORR conditions. In this sense, for metal site adsorptions, we first determined the most relevant coverage of the metal atom at $0.7 \mathrm{~V}_{\mathrm{RHE}}$ by constructing a surface Pourbaix diagram (Supplementary Figs. 29-31). For carbon site adsorptions, we considered all carbon sites near the single metal atom and reported the most stable binding free energies.

To construct a free energy diagram of ORR to $\mathrm{H}_{2} \mathrm{O}_{2}$, we corrected the calculated electronic energies by adding zero-point energy, enthalpy and entropy of adsorbate at $300 \mathrm{~K}$ obtained from a harmonic oscillator approximation using Atomic Simulation Environment ${ }^{67}$. Since $\mathrm{O}_{2}$ molecule is poorly described by standard DFT calculations, we used the calculated energies of gas-phase $\mathrm{H}_{2} \mathrm{O}$ and $\mathrm{H}_{2}$ molecules, and experimental formation free energies of $\mathrm{H}_{2} \mathrm{O}$ and $\mathrm{H}_{2} \mathrm{O}_{2}$ as references. To take into account the effect of the electrode potential, computational hydrogen electrode (CHE) method was employed ${ }^{68}$. In this method the chemical potential of proton 
and electron pair $\mu\left(H^{+}+e^{-}\right)$is equal to one half of that of gas-phase hydrogen molecule $\left(1 / 2 \mu\left(H_{2}\right)\right)$ at standard conditions, and the effect of the electrode potential is included by shifting the electron free energy by $-e U_{\text {elec }}$, where $e$ and $U_{\text {elec }}$ are elementary charge and electrode potential, respectively.

Water disinfection. A standard lab bacterial Escherichia coli strain was kindly provided by Howard Berg's laboratory. E. coli was cultured to stationary phase in LB broth for $14 \mathrm{~h}$ at $37^{\circ} \mathrm{C}$, harvested by centrifugation at $800 \times g$, washed three times with $0.1 \mathrm{M}$ PBS solution and suspended in $0.1 \mathrm{M} \mathrm{PBS}$ to $\sim 7.1 \times 10^{6}$ c.f.u. $\mathrm{mL}^{-1}$. The electrochemical disinfection measurements were run at $25^{\circ} \mathrm{C}$ in a H-type glass cell separated by a Fumasep FBM bipolar membrane (Fuel Cell Store). $25 \mathrm{~mL}$ of the prepared E. Coli in $0.1 \mathrm{M}$ PBS was injected into the cathodic chamber, with a $1 \mathrm{~cm}^{2}$ Fe-CNT/GDL $\left(0.5 \mathrm{mg} \mathrm{cm}^{-2}\right.$ catalyst loading) serving as the working electrode. A chrono-potentiometric measurement at a fixed current density of $20 \mathrm{~mA} \mathrm{~cm}^{-2}$ was performed to ascertain water disinfection. Another control experiment was run in $25 \mathrm{~mL}$ of bacteria-free electrolyte to calculate the overall $\mathrm{H}_{2} \mathrm{O}_{2}$ concentration and generation rate. The $\mathrm{pH}$ value was noted to maintain $\sim 7.2$ before and after the continuous electrolysis in PBS buffer. Bacterial concentrations and killing rates were measured at different time points during electrolysis using standard spread plating techniques. Each sample was serially diluted and each dilution was plated in triplicate onto $\mathrm{LB}$ agar plates, and incubated at $37^{\circ} \mathrm{C}$ for $12 \mathrm{~h}$. The images of overnight cultured plates were taken with a custom-built dark-field imager equipped with a CCD camera (Point Grey Chameleon).

\section{Data availability}

The data that support the findings of this study are available from the corresponding authors upon reasonable request.

Received: 9 July 2019 Accepted: 8 August 2019

Published online: 05 September 2019

\section{References}

1. Debe, M. K. Electrocatalyst approaches and challenges for automotive fuel cells. Nature 486, 43-51 (2012).

2. Dai, L., Xue, Y., Qu, L., Choi, H.-J. \& Baek, J.-B. Metal-free catalysts for oxygen reduction reaction. Chem. Rev. 115, 4823-4892 (2015).

3. Shao, M., Chang, Q., Dodelet, J.-P. \& Chenitz, R. Recent advances in electrocatalysts for oxygen reduction reaction. Chem. Rev. 116, 3594-3657 (2016).

4. Kulkarni, A., Siahrostami, S., Patel, A. \& Nørskov, J. K. Understanding catalytic activity trends in the oxygen reduction reaction. Chem. Rev. 118, 2302-2312 (2018).

5. Siahrostami, S. et al. Enabling direct $\mathrm{H}_{2} \mathrm{O}_{2}$ production through rational electrocatalyst design. Nat. Mater. 12, 1137-1143 (2013).

6. Yang, S. et al. Toward the decentralized electrochemical production of $\mathrm{H}_{2} \mathrm{O}_{2}$ : a focus on the catalysis. ACS Catal. 8, 4064-4081 (2018).

7. Melchionna, M., Fornasiero, P. \& Prato, M. The rise of hydrogen peroxide as the main product by metal-free catalysis in oxygen reductions. Adv. Mater. 13, 1802920 (2018).

8. Ciriminna, R., Albanese, L., Meneguzzo, F. \& Pagliaro, M. Hydrogen peroxide: a key chemical for today's sustainable development. ChemSusChem 9, 3374-3381 (2016).

9. Fukuzumi, S., Lee, Y. M. \& Nam, W. Solar-driven production of hydrogen peroxide from water and dioxygen. Chem. Eur. J. 24, 5016-5031 (2018).

10. Stamenkovic, V. R. et al. Improved oxygen reduction activity on $\mathrm{Pt}_{3} \mathrm{Ni}(111)$ via increased surface site availability. Science 315, 493-497 (2007).

11. Strasser, P. et al. Lattice-strain control of the activity in dealloyed core-shell fuel cell catalysts. Nat. Chem. 2, 454-460 (2010).

12. Liang, $\mathrm{Y}$. et al. $\mathrm{Co}_{3} \mathrm{O}_{4}$ nanocrystals on graphene as a synergistic catalyst for oxygen reduction reaction. Nat. Mater. 10, 780 (2011).

13. Wu, G., More, K. L., Johnston, C. M. \& Zelenay, P. High-performance electrocatalysts for oxygen reduction derived from polyaniline, iron, and cobalt. Science 332, 443-447 (2011).

14. Wang, J. et al. Design of N-coordinated dual-metal sites: a stable and active Ptfree catalyst for acidic oxygen reduction reaction. J. Am. Chem. Soc. 139, 17281-17284 (2017).

15. Verdaguer-Casadevall, A. et al. Trends in the electrochemical synthesis of $\mathrm{H}_{2} \mathrm{O}_{2}$ : enhancing activity and selectivity by electrocatalytic site engineering. Nano Lett. 14, 1603-1608 (2014).

16. Choi, C. H. et al. Tuning selectivity of electrochemical reactions by atomically dispersed platinum catalyst. Nat. Commun. 7, 10922 (2016).

17. Jirkovský, J. S. et al. Single atom hot-spots at $\mathrm{Au}-\mathrm{Pd}$ nanoalloys for electrocatalytic $\mathrm{H}_{2} \mathrm{O}_{2}$ production. J. Am. Chem. Soc. 133, 19432-19441 (2011).
18. Choi, C. H. et al. Hydrogen peroxide synthesis via enhanced two-electron oxygen reduction pathway on carbon-coated Pt surface. J. Phys. Chem. C 118, 30063-30070 (2014).

19. Zhaoke, Z., Hau, N. Y., Da-Wei, W. \& Rose, A. Epitaxial growth of Au-Pt-Ni nanorods for direct high selectivity $\mathrm{H}_{2} \mathrm{O}_{2}$ production. Adv. Mater. 28, 9949-9955 (2016).

20. Yang, H. H. \& McCreery, R. L. Elucidation of the mechanism of dioxygen reduction on metal-free carbon electrodes. J. Electrochem. Soc. 147, 3420-3428 (2000).

21. Sarapuu, A., Vaik, K., Schiffrin, D. J. \& Tammeveski, K. Electrochemical reduction of oxygen on anthraquinone-modified glassy carbon electrodes in alkaline solution. J. Electroanal. Chem. 541, 23-29 (2003).

22. Lee, Y.-H., Li, F., Chang, K.-H., Hu, C.-C. \& Ohsaka, T. Novel synthesis of Ndoped porous carbons from collagen for electrocatalytic production of $\mathrm{H}_{2} \mathrm{O}_{2}$. Appl. Catal. B 126, 208-214 (2012).

23. Fellinger, T.-P., Hasché, F., Strasser, P. \& Antonietti, M. Mesoporous nitrogen-doped carbon for the electrocatalytic synthesis of hydrogen peroxide. J. Am. Chem. Soc. 134, 4072-4075 (2012).

24. Sun, Y. et al. Efficient electrochemical hydrogen peroxide production from molecular oxygen on nitrogen-doped mesoporous carbon catalysts. ACS Catal. 8, 2844-2856 (2018).

25. Iglesias, $\mathrm{D}$. et al. $\mathrm{N}$-doped graphitized carbon nanohorns as a forefront electrocatalyst in highly selective $\mathrm{O}_{2}$ reduction to $\mathrm{H}_{2} \mathrm{O}_{2}$. Chem 4, 106-123 (2018).

26. Kim, H. W. et al. Efficient hydrogen peroxide generation using reduced graphene oxide-based oxygen reduction electrocatalysts. Nat. Catal. 1, 282-290 (2018).

27. $\mathrm{Lu}, \mathrm{Z}$. et al. High-efficiency oxygen reduction to hydrogen peroxide catalysed by oxidized carbon materials. Nat. Catal. 1, 156-162 (2018).

28. Chen, S. et al. Designing boron nitride islands in carbon materials for efficient electrochemical synthesis of hydrogen peroxide. J. Am. Chem. Soc. 140, 7851-7859 (2018)

29. Chen, S. et al. Defective carbon-based materials for the electrochemical synthesis of hydrogen peroxide. ACS Sustain. Chem. Eng. 6, 311-317 (2018).

30. Meurig, T. J., Robert, R. \& W., L. D. Single-site heterogeneous catalysts. Angew. Chem. Int. Ed. 44, 6456-6482 (2005).

31. Yan, D. et al. Defect chemistry of nonprecious-metal electrocatalysts for oxygen reactions. Adv. Mater. 29, 1606459 (2017).

32. Liu, J. Catalysis by supported single metal atoms. ACS Catal. 7, 34-59 (2017).

33. Wei, S. et al. Direct observation of noble metal nanoparticles transforming to thermally stable single atoms. Nat. Nanotechnol. 13, 856-861 (2018).

34. Wang, A., Li, J. \& Zhang, T. Heterogeneous single-atom catalysis. Nat. Rev. Chem. 2, 65-81 (2018).

35. Chen, Y. et al. Single-atom catalysts: synthetic strategies and electrochemical applications. Joule 2, 1242-1264 (2018).

36. Jiao, Y., Zheng, Y., Davey, K. \& Qiao, S. Z. Activity origin and catalyst design principles for electrocatalytic hydrogen evolution on heteroatom-doped graphene. Nat. Energy 1, 16130 (2016).

37. Jiang, K. et al. Transition-metal single atoms in a graphene shell as active centers for highly efficient artificial photosynthesis. Chem 3, 950-960 (2017).

38. Jiang, $\mathrm{K}$. et al. Isolated $\mathrm{Ni}$ single atoms in graphene nanosheets for highperformance $\mathrm{CO}_{2}$ reduction. Energy Environ. Sci. 11, 893-903 (2018).

39. Yang, $\mathrm{H}$. B. et al. Atomically dispersed $\mathrm{Ni}(\mathrm{I})$ as the active site for electrochemical $\mathrm{CO}_{2}$ reduction. Nat. Energy 3, 140-147 (2018).

40. Deng, D. et al. A single iron site confined in a graphene matrix for the catalytic oxidation of benzene at room temperature. Sci. Adv. 1, 1500462 (2015).

41. Hackett, S. F. J. et al. High-activity, single-site mesoporous $\mathrm{Pd} / \mathrm{Al}_{2} \mathrm{O}_{3}$ catalysts for selective aerobic oxidation of allylic alcohols. Angew. Chem. Int. Ed. 119, 8747-8750 (2007).

42. Fei, H. et al. Atomic cobalt on nitrogen-doped graphene for hydrogen generation. Nat. Commun. 6, 8668 (2015)

43. Bergmann, A., Zaharieva, I., Dau, H. \& Strasser, P. Electrochemical water splitting by layered and 3D cross-linked manganese oxides: correlating structural motifs and catalytic activity. Energy Environ. Sci. 6, 2745-2755 (2013).

44. Back, S., Lim, J., Kim, N.-Y., Kim, Y.-H. \& Jung, Y. Single-atom catalysts for $\mathrm{CO}_{2}$ electroreduction with significant activity and selectivity improvements. Chem. Sci. 8, 1090-1096 (2017).

45. Tedsree, K. et al. Hydrogen production from formic acid decomposition at room temperature using a Ag-Pd core-shell nanocatalyst. Nat. Nanotechnol. 6, 302-307 (2011)

46. Xiang, Y. et al. Long-chain terminal alcohols through catalytic $\mathrm{CO}$ hydrogenation. J. Am. Chem. Soc. 135, 7114-7117 (2013).

47. Li, T. et al. Atomic imaging of carbon-supported Pt, Pt/Co, and Ir@Pt nanocatalysts by atom-probe tomography. ACS Catal. 4, 695-702 (2014).

48. Schmidt, J. E., Oord, R., Guo, W., Poplawsky, J. D. \& Weckhuysen, B. M. Nanoscale tomography reveals the deactivation of automotive copperexchanged zeolite catalysts. Nat. Commun. 8, 1666 (2017). 
49. Gong, K., Du, F., Xia, Z., Durstock, M. \& Dai, L. Nitrogen-doped carbon nanotube arrays with high electrocatalytic activity for oxygen reduction. Science 323, 760-764 (2009).

50. Zitolo, A. et al. Identification of catalytic sites for oxygen reduction in ironand nitrogen-doped graphene materials. Nat. Mater. 14, 937 (2015).

51. Gewirth, A. A., Varnell, J. A. \& DiAscro, A. M. Nonprecious metal catalysts for oxygen reduction in heterogeneous aqueous systems. Chem. Rev. 118 2313-2339 (2018).

52. Hyuck, C. C. et al. Unraveling the nature of sites active toward hydrogen peroxide reduction in Fe-N-C catalysts. Angew. Chem. Int. Ed. 56, 8809-8812 (2017).

53. Bonakdarpour, A. et al. Impact of loading in RRDE experiments on Fe-N-C catalysts: two- or four-electron oxygen reduction? Electrochem. Solid-State Lett. 11, B105-B108 (2008).

54. Siahrostami, S., Li, G.-L., Nørskov, J. K. \& Studt, F. Trends in adsorption energies of the oxygenated species on single platinum atom embedded in carbon nanotubes. Catal. Lett. 147, 2689-2696 (2017).

55. Chen, Z. et al. Development of a reactor with carbon catalysts for modularscale, low-cost electrochemical generation of $\mathrm{H}_{2} \mathrm{O}_{2}$. React. Chem. Eng. 2, 239-245 (2017).

56. Lefèvre, M., Proietti, E., Jaouen, F. \& Dodelet, J.-P. Iron-based catalysts with improved oxygen reduction activity in polymer electrolyte fuel cells. Science 324, 71-74 (2009)

57. Jia, Q. et al. Experimental observation of redox-induced $\mathrm{Fe}-\mathrm{N}$ switching behavior as a determinant role for oxygen reduction activity. ACS Nano $\mathbf{9}$ 12496-12505 (2015).

58. Kramm, U. I. et al. On an easy way to prepare metal-nitrogen doped carbon with exclusive presence of $\mathrm{MeN}_{4}$-type sites active for the ORR. J. Am. Chem. Soc. 138, 635-640 (2016).

59. $\mathrm{Li}$, J. et al. Structural and mechanistic basis for the high activity of Fe-N-C catalysts toward oxygen reduction. Energy Environ. Sci. 9, 2418-2432 (2016).

60. Alvarez, P. J. J., Chan, C. K., Elimelech, M., Halas, N. J. \& Villagrán, D. Emerging opportunities for nanotechnology to enhance water security. Nat. Nanotechnol. 13, 634-641 (2018).

61. Liu, C. et al. Conducting nanosponge electroporation for affordable and highefficiency disinfection of bacteria and viruses in water. Nano Lett. 13, 4288-4293 (2013).

62. Liu, C. et al. Rapid water disinfection using vertically aligned $\mathrm{MoS}_{2}$ nanofilms and visible light. Nat. Nanotechnol. 11, 1098 (2016).

63. Paulus, U. A., Schmidt, T. J., Gasteiger, H. A. \& Behm, R. J. Oxygen reduction on a high-surface area Pt/Vulcan carbon catalyst: a thin-film rotating ringdisk electrode study. J. Electroanal. Chem. 495, 134-145 (2001).

64. Kresse, G. \& Furthmüller, J. Efficiency of ab-initio total energy calculations for metals and semiconductors using a plane-wave basis set. Comp. Mater. Sci. 6, 15-50 (1996).

65. Kresse, G. \& Joubert, D. From ultrasoft pseudopotentials to the projector augmented-wave method. Phys. Rev. B 59, 1758-1775 (1999).

66. Wellendorff, J. et al. Density functionals for surface science: Exchangecorrelation model development with Bayesian error estimation. Phys. Rev. B 85, 235149 (2012).

67. Bahn, S. R. \& Jacobsen, K. W. An object-oriented scripting interface to a legacy electronic structure code. Comput. Sci. Eng. 4, 56-66 (2002).

68. Nørskov, J. K. et al. Origin of the overpotential for oxygen reduction at a fuelcell cathode. J. Phys. Chem. B 108, 17886-17892 (2004).

\section{Acknowledgements}

This work was supported by the Rowland Fellows Program at Rowland Institute, Harvard University, and Rice University. This work was performed in part at the Center for Nanoscale Systems (CNS), a member of the National Nanotechnology Infrastructure
Network (NNIN), which was supported by the National Science Foundation under NSF award no. ECS-0335765. CNS is part of Harvard University. Some of the XAS experiments described in this paper were performed at the Canadian Light Source, which is supported by NSERC, the National Research Council Canada, the Canadian Institutes of Health Research, the Province of Saskatchewan, Western Economic Diversification Canada, and the University of Saskatchewan. This research used resources of the 8-ID (ISS) beamline of the National Synchrotron Light Source II, U.S. Department of Energy (DOE) Office of Science User Facilities operated for the DOE Office of Science by Brookhaven National Laboratory under Contract No. DE-SC0012704. The computational part of the work was supported by the U.S. Department of Energy, Office of Science, Office of Basic Energy Science, via Grant DE-SC0008685 to the SUNCAT Center for Interface Science and Catalysis. S.S. acknowledges the support from the University of Calgary's Canada First Research Excellence Fund Program, the Global Research Initiative in Sustainable Low Carbon Unconventional Resources. H.W. acknowledges the support from Taute Lab in Rowland Institute at Harvard.

\section{Author contributions}

This project was conceptualized by K.J. and H.W. and supervised by H.W.; K.J. performed experimental work with the help of C.X. and H.W.; S.B. and S.S. designed and performed computational work with the discussion with J.K.N.; A.J.A performed APT characterization; Y.H. and E.S. helped on XAS tests; W.L. performed HAADF-STEM characterization; D.S. helped on E. coli experiments. K.J., S.B., S.S. and H.W. wrote the manuscript with the discussion with all authors.

\section{Additional information}

Supplementary Information accompanies this paper at https://doi.org/10.1038/s41467 019-11992-2.

Competing interests: A.U.S. provisional patent application, No. 62/779,590, entitled "Tuning of transition-metal single atom coordination for selective oxygen reduction towards hydrogen peroxide", has filed based on the technology described in this work on December 14, 2018 by K.J. and H.W. at Harvard University. The remaining authors declare no competing interests.

Reprints and permission information is available online at http://npg.nature.com/ reprintsandpermissions/

Peer review information: Nature Communications thanks the anonymous reviewer(s) for their contribution to the peer review of this work. Peer reviewer reports are available.

Publisher's note: Springer Nature remains neutral with regard to jurisdictional claims in published maps and institutional affiliations.

Open Access This article is licensed under a Creative Commons Attribution 4.0 International License, which permits use, sharing, adaptation, distribution and reproduction in any medium or format, as long as you give appropriate credit to the original author(s) and the source, provide a link to the Creative Commons license, and indicate if changes were made. The images or other third party material in this article are included in the article's Creative Commons license, unless indicated otherwise in a credit line to the material. If material is not included in the article's Creative Commons license and your intended use is not permitted by statutory regulation or exceeds the permitted use, you will need to obtain permission directly from the copyright holder. To view a copy of this license, visit http://creativecommons.org/ licenses/by/4.0/.

(c) The Author(s) 2019 